\title{
O TRABALHO AUTOGESTIONÁRIO EM COOPERATIVAS DE PRODUÇÃO: o paradigma revisitado*
}

\author{
Jacob Carlos Lima
}

O debate sobre cooperativismo de trabalho e produção no movimento operário e sindical, no final do século XIX, dividia aqueles que consideravam suas possibilidades revolucionárias daqueles que acreditavam em seu caráter reformista: um passo para a revolução socialista ou uma adesão aos princípios capitalistas?

No final do século XX e início do XXI, o debate retorna em outros termos. As experiências socialistas de modelo soviético não deram certo, a eliminação do mercado mostrou ser ineficaz, e as transforma-

* Pesquisa desenvolvida junto aos Departamentos de Ciências Sociais da Universidade Federal da Paraíba e da Universidade Federal de São Carlos, com apoio do CNPq. Versão preliminar do texto foi apresentada no GT "Trabalhadores, sindicatos e a nova questão social" no $27^{\circ}$ Encontro Anual da Anpocs, Caxambu, 2003.

Artigo recebido em novembro/2003

Aprovado em julho/2004 ções capitalistas mudaram o perfil da classe trabalhadora. A crise da sociedade salarial ou do modelo fordista, que agregou direitos sociais à relação de trabalho, reapresentou a necessidade de buscar formas alternativas de organização do trabalho e de autonomia dos trabalhadores, diante do crescimento do desemprego, da perda dos direitos sociais do período anterior e do enfraquecimento do movimento sindical. A proposta de cooperativismo de trabalho, juntamente com outras formas associativas de organização dos trabalhadores, tem sido recuperada com o objetivo de dar continuidade à luta por uma sociedade mais igualitária e socialista, no novo contexto do desenvolvimento capitalista.

Entretanto, permanece a polêmica sobre a possibilidade efetiva de as cooperativas se constituírem em avanço na direção da maior democratização do trabalho, pela autogestão e posse coletiva dos meios de produção, superando assim a subordinação ao capital. As cooperativas são percebidas 
também como uma forma alternativa de empresa capitalista, na qual o trabalho autogestionário termina por ser funcional pela flexibilidade que possibilita no uso da força de trabalho, permitindo a redução de custos e aumentando a competitividade das empresas. Esse debate recupera, em grande parte, a tese da degenerescência das cooperativas, desenvolvida por Webb e Webb (1914), que previa, de forma pessimista, que o sucesso das cooperativas significaria a eliminação da democracia autogestionária e sua transformação em empresas capitalistas comuns. Poderíamos acrescentar que, com a reestruturação produtiva e a formação das redes empresariais, as cooperativas, embora não necessariamente se transformem em empresas comuns, podem terminar integrando essas redes como parceiras terceirizadas numa relação assimétrica, oferecendo força de trabalho a baixo custo e apenas quando necessário. Em outras palavras, o debate reacende a polêmica do século XIX sobre a existência de cooperativas falsas - como linha auxiliar do capital, e de cooperativas verdadeiras - que assumem o caráter autogestionário e solidário na perspectiva de emancipação dos trabalhadores.

Trazendo o debate para a situação brasileira atual, analisamos dois grupos de cooperativas de trabalho e/ou de produção, ${ }^{1}$ ambos resultantes das mudanças do capitalismo contemporâneo. No primeiro grupo, estão as cooperativas "pragmáticas" (que podem incluir as chamadas "falsas cooperativas" ou cooperfraudes), que funcionam terceirizadas para empresas e, em geral, foram organizadas por essas mesmas empresas, ou ainda, integram programas estatais de geração de renda, desvinculadas dos princípios do movimento cooperativista. No segundo grupo, as cooperativas "defensivas", formadas a partir de movimentos de trabalhadores para manutenção do emprego em fábricas em situação falimentar, ou de programas governamentais de geração de renda para populações pobres. Estas são apoiadas por sindicatos, ONGs e instituições da sociedade civil e enquadram-se na proposta de "economia solidária”, na qual os valores da autogestão dos trabalhadores, o combate ao desemprego e o desenvolvimento sustentável são norteadores. Nos dois grupos, predomina uma grande dependência, seja de redes empresariais e órgãos públicos - nas chamadas cooperativas pragmáticas -, seja de órgãos públicos de fomento e instituições da sociedade civil - nos chamados empreendimentos solidários. Essa dependência afeta diretamente a percepção dos trabalhadores sobre o trabalho autogestionário e suas perspectivas futuras.

Neste artigo, pretendemos verificar as similaridades e as diferenças na organização dessas cooperativas, recuperando algumas situações específicas no Brasil e as dificuldades presentes na formação de uma cultura autogestionária entre os trabalhadores, considerando que o trabalho nessas cooperativas, mais que uma alternativa voluntária, responde a um quadro de desemprego estrutural. Ao mesmo tempo, indagamos em que medida é possível construir uma alternativa de produção e gestão do trabalho ao capitalismo inserida no mercado capitalista. Recuperamos, então, a literatura e pesquisas recentes sobre o tema, nas quais os numerosos "casos" apontam tendências em um quadro ainda em construção.

\section{Recuperando o modelo}

As cooperativas de trabalho e de produção surgem com o trabalho industrial e com o movimento operário no século XIX. O movimento cooperativista fundou-se inicialmente com os socialistas utópicos, que propunham a autogestão do trabalho como reação defensiva ao desemprego e às condições vida e de trabalho dos operários industriais. Com princípios democráticos e igualitários, propunha o associativismo no trabalho ainda dentro do capitalismo ou como forma de superar o capitalismo. O ano de 1844 é considerado o marco do movimento cooperativista com a criação em Rochdale, perto de Manchester, Inglaterra, da Rochdale Society of Equitable Pionner, uma cooperativa de consumo de operários têxteis que se expandiu rapidamente com a abertura, em 1850, de uma cooperativa de produção industrial - um moinho - e, em 1854, uma tecelagem e fiação.

O movimento não parou de crescer e em 1852, na Inglaterra, foi promulgada a lei das Sociedades Industriais e Cooperativas, que passou a regular as 
relações das cooperativas com o Estado. Em 1895, em Genebra, foi criada a Aliança Cooperativa Internacional, que ratificou os princípios de Rochdale: a adesão voluntária e livre de seus membros; a gestão democrática; a participação econômica dos membros na criação e no controle do capital; a educação e a formação dos sócios; a intercooperação no sistema cooperativista. Desde o início, entretanto, surgiram denúncias da existência de falsas cooperativas, uma das artimanhas de empresários para pagarem menores salários.

Embora originário do movimento operário e socialista de contestação ao capital e constituindo-se em alternativa ao modelo de produção capitalista, o movimento cooperativista foi apropriado também por propostas reformistas de inspiração cristã, direcionadas à humanização das relações entre capital e trabalho.

Ora visto como alternativa ao capitalismo, ora como possibilidade dentro do capitalismo, o cooperativismo marcou a esquerda da época. Marx (1977) destacou o avanço do cooperativismo no combate ao capitalismo, mas ressalvava o risco de os trabalhadores se autoexplorarem, dado o fato de serem patrões de si mesmos e dadas as imposições do mercado à produção. À ambigüidade de Marx somou-se a crítica de Luxemburg (1979), para quem o fato contraditório de os operários desempenharem o papel de trabalhadores e patrões de si mesmos inviabilizaria as cooperativas de produção, impondo-lhes escolher entre transformarem-se em empresas capitalistas ou dissolverem-se.

Essa contradição deu origem à chamada "tese da degeneração das cooperativas" de Webb e Webb (1914), os quais sustentavam que as democracias de produtores terminariam por sucumbir às necessidades empresariais e se transformariam em associações de capitalistas com a incorporação do lucro e a contratação de trabalhadores assalariados. Uma outra crítica ao movimento afirma que as cooperativas desviariam a atenção dos trabalhadores dos desafios mais amplos apresentados pelo capitalismo, fazendo com que aceitassem os ditames do mercado e permitissem a reificação dos seus interesses, que se voltariam contra os próprios trabalhadores (Mandel, 1975; Clarke, 1977 apud Batstone, 1983). A tensão existente en- tre democracia e eficiência estaria, dessa forma, entre os motivos de sua inviabilidade.

Durante o século XX, esse debate contrapôs, no movimento socialista, a perspectiva centralizadora do socialismo soviético às experiências autogestionárias de inspiração socialista que frutificaram em países capitalistas como França e Itália com forte apoio estatal. Louis (1986), fazendo referência às cooperativas de trabalho européias da primeira metade do século XX, formadas por trabalhadores sem qualificações e organizadas em frentes de trabalho, afirma que elas raramente observavam princípios cooperativistas e apenas mantinham-se em situações de crise e com ganhos mínimos para os trabalhadores.

Mesmo assim, França e Itália mantiveram um movimento cooperativista significativo durante todo o século XX. Ao analisar o caso italiano, Thornley (1983) destaca três fatores implicados no crescimento das cooperativas de trabalho e de produção no país. O primeiro seria a proximidade do movimento cooperativista dos partidos políticos - existem três confederações no país, a Lega Nazionale delle Cooperative Mutue, fundada em 1893, com forte apoio de socialistas e comunistas, a Confederazione Cooperative Italiane, de origem católica, e a Associazione Generale delle Cooperative Italiane, vinculada aos social-democratas e republicanos. O apoio dos diversos partidos e das tendências políticas garantiram de forma contínua um suporte político às cooperativas e suas confederações.

O segundo fator seria o forte apoio estatal no século XIX, que se manteve e se fortaleceu no pós-1945, ${ }^{2}$ com exceção do período fascista durante o qual a Lega e a Confederazione foram postas na ilegalidade. A constituição italiana incluiu o reconhecimento das cooperativas como forma especial de empresa, fundadas no princípio da mutualidade e apoiadas pelo Ministério do Trabalho e da Segurança Social. As cooperativas gozam de isenção de taxas, condições especiais de empréstimos bancários, facilidades de acesso a contratos de obras públicas, assim como de incentivos a processos de recuperação de empresas falidas para manter empregos. O apoio estatal e a proximidade dos partidos garantiram o terceiro aspecto: as 
perspectivas comerciais favoráveis, por meio de contratos com clientes nacionais e internacionais simpatizantes da causa cooperativista.

As cooperativas dos países socialistas, pela sua subordinação ao Estado, nunca foram consideradas como tais, uma vez que os princípios cooperativistas de adesão voluntária e autogestão não eram efetivamente observados. A experiência iugoslava de socialismo de mercado parece ter mais se aproximado do ideal cooperativista de autogestão dos trabalhadores, mas o planejamento estatal permaneceu preponderante. ${ }^{3}$ Outra experiência a destacar é a do Kibutz israelense, resultado do movimento sionista de migração para a Palestina e que se constituiu em unidades de produção autônoma dentro do Estado de Israel. O movimento, no entanto, foi afetado pela permanente economia de guerra do país. ${ }^{4}$

Por fim, no País Basco espanhol encontra-se o modelo de cooperativismo de produção (atualmente múltiplo) formado por uma rede de cooperativas surgidas na década de 1950 e reestruturadas nos anos de 1970, a partir dos novos parâmetros de competitividade: Mondragón. ${ }^{5}$ O Complexo de Mondragón, que se constitui em um dos principais produtores de eletrodomésticos de linha branca do país e de carrocerias de ônibus, entre diferentes produtos, com filiais em outros países inclusive fora da Europa, é visto como exemplo das possibilidades das cooperativas, pautadas pelos princípios autogestionários e de intercooperação, funcionando com uma rede e mantendo competitividade por meio de inovações tecnológicas e organizacionais. ${ }^{6}$

A reestruturação econômica a partir de 1970, com o fechamento e o deslocamento de fábricas, o declínio de regiões industriais, a abertura e a internacionalização dos mercados, o colapso do socialismo de Estado, entre outros fatores que irão compor o que chamamos de globalização, provocou a retomada do cooperativismo como alternativa ao desemprego crescente, provocando o renascimento do interesse sobre o tema e a multiplicação de empresas cooperativas, agora consideradas em um novo momento do desenvolvimento capitalista.

\section{Reestruturação econômica e coopera- tivismo de trabalho e produção}

A atual onda de empreendimentos cooperativos é resultante de duas situações convergentes. A primeira delas refere-se à reestruturação econômica, à crise do fordismo e ao surgimento do que os economistas da escola regulacionista chamam de acumulação flexível. Esta implicou a reestruturação organizacional das empresas a par de profundas inovações tecnológicas decorrentes da chamada revolução informacional, com a eliminação de barreiras geográficas à produção, a formação de empresas em rede, a terceirização de atividades, a desregulamentação dos mercados, a flexibilização das relações de trabalho com a eliminação de direitos sociais conquistados pelos trabalhadores, a partir da segunda metade do século XX. O fechamento de fábricas e empresas, a desregulamentação dos mercados de trabalho, o enfraquecimento do sindicalismo e o desemprego foram algumas das conseqüências de impacto para os trabalhadores.

Outro aspecto desse ressurgimento são os movimentos contraculturais do final da década de 1960, o desencanto com o capitalismo e com o socialismo de Estado, o surgimento de movimentos ecológicos, feministas e de minorias, e a busca de alternativas ante os modelos existentes. Numa perspectiva culturalista do desenvolvimento são questionadas as mudanças econômicas como fator de progresso e justiça social, além dos desastres ambientais de uma sociedade baseada no industrialismo com a utilização de fontes de energia não renováveis e altamente poluentes. Os resultados igualmente desastrosos de "engenharias sociais" promovidas pelo Estado, e a crescente crise fiscal desse mesmo Estado, a defesa da democracia e da maior participação da sociedade nas decisões constituem-se em meio propício para o questionamento da ordem vigente dos dois lados do muro de Berlim. As experiências associativas aparecem, mais uma vez, como alternativa.

Nos países em desenvolvimento, também a partir dos anos de 1970, as cooperativas foram propostas por órgãos internacionais como forma de engajar a sociedade nos projetos de desenvol- 
vimento e, dessa forma, aliviar as pressões sobre o Estado. O caráter conservador da proposta se manifestava, na América Latina, em sua utilização por governos militares para a resolução de problemas agrários sem alterar as estruturas dominantes. Em países do subcontinente indiano e da África, é forte a presença de cooperativas em programas estatais de desenvolvimento, entretanto poucos deles observam os princípios do cooperativismo, constituindo-se, sobretudo, em formas de geração de renda e organização de produtores rurais.

Seja como alternativa de ocupação, manutenção de empregos ou de geração de renda, o modelo associativo vem se multiplicando. Cornforth (1983) utiliza uma tipologia para classificar as cooperativas de trabalho e produção, surgidas no pós-1970, que reflete as mudanças econômicas, políticas e culturais do período. Com algumas adaptações, podemos assim caracterizá-las: a primeira delas, chamada Endowed Co-operatives são propostas advindas dos proprietários de empresas. Nessas situações, as motivações empresariais variam desde idéias socialistas cristãs, até o pragmatismo decorrente do interesse em se manter na empresa, a falta de herdeiros, ou mesmo o risco de perda da empresa por questões gerenciais, prejuízos econômicos etc. No geral, problemas financeiros levam a essa situação. Constituem-se então em empresas autogestionárias, nas quais os funcionários participam do controle acionário, que, no entanto, se mantém ainda com os proprietários. A organização do trabalho pouco muda, e a democracia no trabalho, que raramente existe, conserva a hierarquia anterior.

As cooperativas "defensivas", ou cooperativas "fênix" (Mellor, Hannah e Stirling, 1988), são formadas pelos operários visando a manter os empregos a despeito do fechamento ou da falência de fábricas e empresas. Geralmente, a formação da cooperativa é o último recurso quando outras ações de recuperação falharam. Resulta, assim, que essas cooperativas surgem com numerosos problemas, além de apresentarem uma situação comercial difícil. As fábricas, tecnologicamente defasadas e com baixa produtividade, perdem clientes e mercados. A nova estrutura depende do investimento de trabalho dos operários, boa vontade de clientes e fornecedores, além da ajuda efetiva de sindicatos e de órgãos governamentais. A formação de uma cultura autogestionária é um processo lento e complexo, e grande parte dos operários e do staff administrativo abandona a cooperativa.

As cooperativas "alternativas" resultam de movimentos contraculturais dos anos de $1960 \mathrm{e}$ 1970, e seus membros são oriundos de classe média, bem educada, com ideais democráticos, voltados mais a necessidades sociais do que aos lucros. São predominantes nos países capitalistas avançados e são, na maioria das vezes, editoras, livrarias, lojas de comida e/ou produtos naturais, de informática, escolas de línguas e similares. Geralmente, organizam-se em pequenos negócios com as dificuldades de sobrevivência inerentes a esse tipo de empreendimento.

As cooperativas de "geração de renda" surgem com o crescimento do desemprego e visam a criar empregos. Em períodos anteriores, constituíam-se em programas governamentais de obras emergenciais vigentes em momentos de recessão econômica, principalmente na Europa. Em países em desenvolvimento, inclui programas propostos por agências de desenvolvimento que visam à organização de cooperativas em comunidades carentes que, em geral, enfrentam problemas de comercialização de seus produtos. Uma variação dessa estratégia são as cooperativas voltadas à terceirização industrial e criadas por políticas públicas de governos estaduais ou municipais, sindicatos, Igreja Católica e outras instituições. São chamadas também de cooperativas "populares" e estão voltadas igualmente aos desempregados e à população de baixa renda.

As cooperativas "pragmáticas" são cooperativas organizadas com o objetivo de terceirizar atividades de empresas e reduzir custos. Nestas, não existe a preocupação com democracia no trabalho ou autonomia do trabalhador. A finalidade é o trabalhador organizar-se autonomamente e responsabilizar-se pelo empreendimento, livrando a empresa das obrigações sociais. No geral, as empresas garantem, por algum tempo, contratos de compra de produtos ou serviços. São chamadas, ainda, de falsas ou pseudocooperativas por sua desvinculação absoluta dos princípios cooperativistas. Funcionam, entretanto, na manutenção de 
empregos ou na geração de renda em situações de privatização, terceirização e, mesmo, de políticas públicas de apoio a investimentos industriais.

\section{A experiência brasileira recente}

No Brasil, no período anterior à década de 1980, existiram várias experiências de cooperativas de crédito, habitacional e agrícola. Será a partir da segunda metade dessa década, contudo, que as cooperativas de trabalho e de produção começarão a organizar-se e a ganhar visibilidade. A sucessão de crises econômicas do final do período militar, as primeiras manifestações internas das mudanças econômicas com a reestruturação produtiva de fábricas e empresas, a adoção de políticas neoliberais no final da década constituem o cenário do incremento do cooperativismo de trabalho no país.

O fechamento de fábricas e as tentativas de recuperação foram documentados por diversos autores. Holzmann (2001) retratou o caso da fábrica de fogões Wallig, no Rio Grande do Sul, que suspendeu suas atividades em 1984 e, a partir de forte mobilização dos trabalhadores, constituiu duas cooperativas: uma mecânica e uma fundição. Essas cooperativas foram viabilizadas após parte dos trabalhadores se convencer das vantagens de abrir mão de direitos trabalhistas, tornar-se patrões e, dessa forma, manter os empregos. Na fundição ficaram os trabalhadores menos qualificados e, na mecânica, permaneceram os mais qualificados. Em 1991, quando os proprietários ganharam judicialmente a posse dos prédios, apenas a cooperativa mecânica permaneceu. Essa permanência pode ser atribuída à maior escolaridade dos trabalhadores da mecânica e à situação de mercado mais favorável, o que permitiu um melhor desempenho econômico da cooperativa e uma maior adesão dos trabalhadores.

Outra situação de recuperação fabril desse período foi retratada por Nascimento (1993) sobre a Tecelagem Mandacaru, em João Pessoa, Paraíba. Resultado de grande mobilização social dos trabalhadores, o estado assumiu o controle da empresa formando uma cooperativa e garantindo seu fun- cionamento (precário) até seu fechamento no começo dos anos de 1990. Problemas de comercialização, obsoletismo de equipamentos e ausência de cultura associativa condenaram o empreendimento.

Além dessas experiências, que, embora não tenham sido únicas, estão documentadas, outras cooperativas de geração de renda e recuperação de fábricas foram organizadas com apoio de agências de desenvolvimento a partir do final da década de 1970. Destas, destacamos dez cooperativas apoiadas pela InterAmericam Fundation (IAF) no Norte e no Nordeste do país (Cavalcanti, 1988). A maioria dos projetos poderia ser classificada como cooperativa de geração de renda em comunidades sem alternativas de trabalho no Pará, Piauí, Ceará e Rio Grande do Norte. Apenas uma delas, a COMTERN, no Rio Grande do Norte, foi constituída com o fechamento de uma fábrica têxtil quando, influenciados pela experiência da fábrica paraibana já mencionada, os trabalhadores organizaram uma cooperativa por intermédio do sindicato.

As avaliações realizadas sobre os projetos de recuperação destacavam as dificuldades da manutenção das cooperativas e as perspectivas restritas de continuidade, uma vez que as relações com o mercado eram frágeis e todas tinham problemas de comercialização de seus produtos. A exceção foi a fábrica recuperada que produzia etiquetas tecidas e tinha apenas uma concorrente na região, beneficiando-se da crise econômica pela qual passava o setor têxtil como um todo. Além do aporte financeiro da IAF, a fábrica contou com a liberação da hipoteca da maquinaria pelo Banco Estadual e ganhou na justiça uma pendência com o então IAPAS, que exigia da cooperativa o pagamento dos débitos da fábrica (Osório, 1988). Mesmo assim, a cooperativa não constava do registro da Organização Estadual das Cooperativas em 1997 (assim como informações sobre sua existência), o que pode indicar sua possível liquidação ou transformação em empresa regular.

Com a abertura das exportações e a adoção de políticas neoliberais, durante o Governo Collor a partir de 1990, o parque industrial brasileiro sofre profundas transformações para enfrentar a competição internacional. Fábricas são fechadas, setores inteiros são desnacionalizados e outros se reestru- 
turaram. Empresas públicas são privatizadas e o desemprego assume patamares elevados. Nesse momento, podemos falar do início da atual onda de associativismo de trabalho e produção no país.

No setor industrial, um marco do associativismo foi a falência da fábrica de calçados Makerly, em Franca, e sua transformação em empresa autogestionária, em 1992, assessorada pelo Dieese, com a participação de técnicos oriundos do movimento sindical paulista. A assessoria fundamentava-se na experiência dos ESOPs (Employee Stocks Ownership Plans), programa do governo norteamericano para os trabalhadores adquirirem ações das empresas, além das experiências de associações comunitárias e do movimento sindical do ABC. Outros projetos de recuperação de empresas falidas foram implementados, como a Cobertores Parahyba, a Facit e a Hidro-Phoenix. Em 1994, foi organizado em São Paulo, contando com a participação de representantes de seis cooperativas, o I Encontro dos Trabalhadores de Empresas de Autogestão, no qual foi criado a ANTEAG (Associação Nacional dos Trabalhadores em Empresas de Autogestão e Participação Acionária) para assessorar a formação de empresas solidárias (Singer, 2002). ${ }^{7}$

A partir dos anos de 1990, temos a multiplicação de cooperativas "defensivas", "fênix" ou com outras denominações para projetos de recuperação de empresas. A diferença do período é o caráter de rede proposto pela associação, a assessoria especializada e a adesão aos princípios de autogestão e democracia no trabalho (ANTEAG, 2000; Sola, 2000; Nakano, 2000). Posteriormente, a ANTEAG começou a trabalhar juntamente com o governo do Rio Grande do Sul na organização de cooperativas resultantes do deslocamento e do fechamento de fábricas de calçados, e com prefeituras como a de São Paulo.

Ao lado das propostas autogestionárias com fundamentação no movimento sindical, na década de 1990, multiplicou-se também o que foi chamado de "falsas cooperativas", cooperativas tradicionais ou cooperativas pragmáticas. Para efeito deste artigo, as denominaremos "pragmáticas". As empresas capitalistas regulares perceberam que poderiam terceirizar suas atividades de forma bastante vantajosa se organizassem cooperativas para seus trabalhadores. Fazendas produtoras de laranja no estado de São Paulo foram as primeiras a serem denunciadas por essa prática. Do dia para a noite, surgiram cooperativas com mais de mil trabalhadores para colher laranjas. Conhecidas como "coopergatos”, essas empresas utilizavam o intermediário o gato, aliciador de trabalhadores - para organizar empresas cooperativas que as livrassem dos encargos trabalhistas. A justiça interveio e esse procedimento foi abandonado. Entretanto, com o crescimento da focalização das empresas (processo no qual passam a dedicar-se ao produto principal, terceirizando os demais), inúmeras empresas industriais e de serviços passaram a sugerir que seus trabalhadores organizassem cooperativas para a realização de tarefas que elas deixariam de realizar diretamente. Isto aconteceu com empresas elétricas, telefônicas, bancos e indústrias. Mais que cooperativas com propostas autogestionárias de autonomia dos trabalhadores, elas podem ser chamadas de "pragmáticas" ou, em outros termos, voltadas à terceirização de atividades com o objetivo de reduzir custos com a força de trabalho. E a aceitação pelos trabalhadores é igualmente "pragmática": a manutenção de emprego.

Na perspectiva "pragmática", alguns governos estaduais, com a guerra fiscal entre estados e municípios na busca de atração de investimentos industriais, passaram a incluir no "pacote" de incentivos oferecidos às empresas que se instalassem em seus territórios a terceirização industrial em cooperativas de produção organizadas por instituições governamentais. Uma política de desenvolvimento em consonância com os novos paradigmas produtivos. O estado do Ceará, pioneiro na utilização desse processo, buscou atrair empresas de trabalho intensivo, tais como as têxteis, as confecções e os calçados (de origem gaúcha e paulista em sua maioria), as quais deveriam se instalar em cidades do interior do estado. Com esse objetivo, a partir de 1994, foram construídos centros de treinamento e organizaram-se cooperativas de produção industrial em diversos municípios nos quais se instalaram escritórios de empresas calçadistas e de confecções ao lado de galpões industriais de "suas" cooperativas, com uma média de trezentos trabalhadores cada. Um conjunto de cooperativas de confecção vinculado a uma fábri- 
ca de investidores "taiwaneses" chegou a empregar 1.800 trabalhadores (Moreira, 1997). Em 1997, com denúncias de trabalho assalariado disfarçado e a má gestão de algumas cooperativas, parte delas foi fechada ou transformou-se em empresas regulares. Outras continuam funcionando normalmente. A característica dessas cooperativas era trabalhar como faccionistas de empresas na montagem de calçados e na finalização de confecções, e as que permaneceram foram progressivamente se adequando aos estatutos formais das cooperativas sem que as empresas abrissem mão do controle da produção. O impacto dessas cooperativas em municípios sertanejos com uma população média de 20 mil habitantes foi muito grande. Houve a criação de cem a trezentos empregos diretos e foram observados reflexos positivos nas economias locais fazendo com que, por algum tempo, os municípios disputassem a implantação dessas cooperativas.

No caminho aberto pela experiência cearense, a Paraíba e o Maranhão tentaram, com menor êxito, políticas semelhantes. Na Paraíba, a pressão da Procuradoria da República fez o estado abandonar rapidamente essa política, que foi anunciada, inclusive, no folder que visava a atrair empresas para o estado. A autuação da maior cooperativa do estado, vinculada a uma fábrica paulista de calçados (que anunciou no jornal a contratação de empregados para a cooperativa), resultou na contratação de todos os trabalhadores pela fábrica.

No Maranhão, um grande projeto do mesmo grupo taiwanês que atuava no Ceará foi implantado na cidade de Rosário, com a construção de um pólo industrial de confecções que previa a criação de aproximadamente quatro mil empregos "associados". A fábrica-cooperativa funcionou durante nove meses e chegou a empregar novecentos trabalhadores; em seguida, entrou em uma crise que culminou com o afastamento do grupo empresarial (Lima, 2002). No município de Lima Campos, a expansão de uma empresa privada deu-se na forma de cooperativa. A sugestão da transformação da fábrica em cooperativa foi do governo do estado, a partir de programa de geração de renda denominado "Comunidade Viva", com a criação de quinze "Grupos de Trabalhadores". Com isso a fábrica foi desativada e foram criados os "Grupos de Trabalhadores" coordenados pela empresa e que contavam, em 2003, com cerca de duzentos trabalhadores associados (Reis, 2003).

Outras experiências foram implantadas em municípios do Rio Grande do Norte e Pernambuco, vinculadas a grupos políticos ou a fábricas em processo de terceirização, e parte ainda continua funcionando, apesar da constante fiscalização. Quando a cooperativa trabalha exclusivamente para uma empresa, esta controla o processo produtivo, além de manter suas máquinas em regime de comodato. Outras cooperativas, organizadas gerencialmente, buscam diversificar contratos para evitar dependências. Nesses casos, contam com empréstimos do Banco do Nordeste, além dos incentivos dos governos estaduais.

Antes de serem implementadas no Nordeste como "política social", experiências semelhantes foram organizadas em outros países. Na Espanha, foram implantadas principalmente na Galícia e na Andaluzia, regiões consideradas menos desenvolvidas. Nestas, parcerias com grandes empresas (cadeias de lojas ou indústrias), Igreja Católica e outros setores sociais organizaram cooperativas de confecções, empregando principalmente mulheres que passaram a trabalhar "em rede" para essas empresas dentro dos parâmetros da flexibilidade e da competitividade internacional. Ao contrário de Mondragón, no País Basco, não se formou um complexo cooperativo autônomo, mas se criaram redes de cooperativas profundamente dependentes das empresas (Herranz e Hoss, 19901991; Baldacchino, 1990).

Em comum, nessas cooperativas, havia a presença formal da autogestão, com conselhos fiscais e diretoria eleita, mas vinculadas às empresas primeiras. O caráter pragmático refere-se à associação Estado-empresas na fórmula geração de emprego e renda e, principalmente, redução de custos (Lima, 2002).

\section{Cooperativas, sindicalismo e economia solidária}

Num contexto de reestruturação econômica e reformas neoliberais no país, com a redução do emprego formal, com o crescimento da informali- 
dade, do chamado desemprego estrutural e da decorrente desarticulação do sindicalismo, a busca por alternativas deu-se, inicialmente, como reações a casos pontuais para a manutenção de empregos. Observamos, em seguida, o envolvimento de sindicatos na luta de operários ameaçados de desemprego devido ao fechamento de fábricas e, a partir da mobilização dos trabalhadores, o apoio à formação de cooperativas. A Federação Democrática dos Sapateiros do Rio Grande do Sul, filiada à CUT, com o fechamento sistemático de fábricas no pólo calçadista do Vale dos Sinos, a partir de 1995-1996, passou a apoiar a formação de cooperativas de produção e de trabalho, por meio do aval a linhas de créditos destinadas à compra de máquinas, à formação profissional, à assessoria e à formação de parcerias com empresas.

O sindicato dos trabalhadores calçadistas do Ceará, num primeiro momento, em 1997, passou a combater a organização de "cooperativas pragmáticas" em campanha contra a instalação de "falsas cooperativas" no interior do estado. A reivindicação, na época, era eliminar as cooperativas por meio de seu fechamento ou por sua transformação em empresa regular. A campanha contra as cooperativas promovidas pelo sindicato provocou, inicialmente, a desconfiança dos trabalhadores cooperados na atuação do Sindicato por considerarem uma ameaça direta aos seus empregos. As empresas aumentavam essa desconfiança ameaçando o fechamento das unidades fabris, em tese, as cooperativas (Lima e Araújo, 1999).

Por largo tempo, os sindicatos não discutiram o problema dos trabalhadores associados. Seja pelo seu número restrito, seja por não terem, até então, se constituído em problema. Esses trabalhadores eram vistos como autônomos e, portanto, fora do sindicato.

A partir do final de 1997, essa situação foi alterada com o início de discussões mais sistemáticas, promovidas pela Central Única dos Trabalhadores, que propunha o debate sobre as cooperativas, segundo os princípios da Economia Solidária.

A maior visibilidade dos trabalhadores cooperados em países como a Itália, França e Espanha fez com que, historicamente, conforme as especificidades políticas nacionais, representantes sindi- cais participassem das cooperativas e de suas federações. No caso espanhol, foram significativos os debate sobre a presença sindical em Mondragón, no período pós-franquista, nos movimentos pela equiparação de direitos entre trabalhadores associados e os trabalhadores assalariados, e a possibilidade de sindicalização dos associados (White e White, 1989). ${ }^{8}$

Segundo Singer, o conceito de Economia Solidária possui diversas acepções (Economia Social, Economia Popular), mas conserva, em comum, a contraposição entre a solidariedade e o individualismo competitivo predominante na sociedade capitalista. Trata-se de organizações de produtores em forma de autogestão: na igualdade de direitos de todos os membros; na propriedade comum do capital, numa distribuição mais igualitária, bem como em sua gestão democrática. A cooperativa seria, por excelência, o tipo ideal de empreendimento solidário, voltado aos desempregados, aos trabalhadores em via de perder o emprego e aos pobres. Constitui-se resposta à reestruturação econômica capitalista e às suas conseqüências na precarização do trabalho e da vida social (Singer, 2000, 2002, 2003).

A retomada da idéia de cooperativismo considera, igualmente, as mudanças tecnológicas e organizacionais das últimas décadas, a crise do fordismo e do assalariamento e a adoção do trabalho flexível como novo paradigma da organização da produção e do trabalho. A flexibilidade na organização do trabalho é valorizada em seus aspectos positivos, considerando-se a maior participação e autonomia do trabalhador na base, por meio das células de produção e do trabalho em equipe bem como da valorização do conhecimento operário. Os aspectos positivos terminam, contudo, por ser anulados em decorrência da intensificação do trabalho, do desemprego e da exclusão social ocasionados pela flexibilização.

A distinção entre o novo representado pelo cooperativismo solidário e o velho representado pelo cooperativismo tradicional (leia-se as "cooperativas pragmáticas") reapresenta a questão do cooperativismo "degenerado", que abandonou os princípios do movimento cooperativista e se transformou apenas numa variante das empresas capi- 
talistas regulares. Recupera-se, assim, o debate iniciado no século XIX em torno da tese da degenerescência das cooperativas.

A proposta de Economia Solidária foi incorporada ao movimento sindical. Em 1999, a CUT organizou em São Paulo, um seminário internacional sobre desenvolvimento solidário, que culminou na criação da Agência de Desenvolvimento Solidário, ADS, cujos objetivos eram criar novas oportunidades de renda e trabalho em organizações de caráter solidário, contribuindo com alternativas para um desenvolvimento social e sustentável, além de criar um Sistema Nacional de Crédito Cooperativo, educar trabalhadores na perspectiva solidária, viabilizar a inserção dos empreendimentos solidários no mercado, difundir os princípios da economia solidária no mercado e criar um novo cooperativismo (combatendo as falsas cooperativas). O Sindicato dos Metalúrgicos do ABC, em seu terceiro congresso, realizado no ano 2000, aprovou resolução de incentivo ao cooperativismo como alternativa de trabalho e renda, aprovou a associação dos cooperados ao sindicato e se propôs a apoiar a criação de cooperativas de produção. A partir dos dois eventos, o movimento sindical passou a responder a uma situação de fato: a multiplicação da produção na forma de trabalho cooperado, na qual, em tese, o trabalhador desempenharia papel central. Além disso, o Sindicato dos Químicos do ABC e um grupo de cooperativas formaram a Unisol Cooperativas associação de defesa e apoio desses empreendimentos por meio da busca de linhas de financiamento e promoção de qualificação e requalificação profissional, voltadas ao trabalho associado e a funções de assessoria semelhantes às da ANTEAG (Magalhães, 2001; Magalhães e Todeschini, 2000; Singer, 2002).

Outra proposta implementada foi da formação das Incubadoras Tecnológicas de Cooperativas Populares, criadas pela Coppe/UFRJ, com apoio da Finep e do Banco do Brasil, voltadas à organização de empreendimentos comunitários. Em 1998, foi lançado o PRONINC (Programa Nacional de Incubadora de Cooperativas), para ampliar o número de incubadoras nas universidades e, a partir de 1999, foi criada a rede de incubadoras vinculada à Fundação Unitrabalho. Esses programas contaram com forte apoio da rede Cáritas brasileira e internacional, instituição católica de apoio à ação social da Igreja (Singer, 2002).

Nesta perspectiva, o governo petista do Rio Grande do Sul criou, em 1999, o Programa de Economia Popular e Solidária, dirigido pela Coordenação de Economia Popular e Solidária (ECOPOPSOL), da Secretaria do Desenvolvimento e Assuntos Internacionais (SEDAI), com apoio da ANTEAG. Desde então, foram criadas em torno de 120 cooperativas, nos diversos ramos da produção e serviços. O programa passou a apoiar cooperativas de produção industrial calçadistas do "Vale dos Sinos", de pequenos produtores e agricultores, de assentados do MST, redes de pequenos proprietários de comércio e serviços, e cooperativas defensivas formadas por antigas indústrias que faliram (Cruz, 2001). Entretanto, com a saída do Partido dos Trabalhadores do governo estadual do Rio Grande do Sul, o programa perdeu prioridade.

\section{Problemas que permeiam o modelo}

O estudo das experiências de trabalho associado em cooperativas, em empreendimentos solidários ou não, aponta para dificuldades inerentes a uma proposta coletivista dentro do capitalismo. Tendo como referência as cooperativas britânicas, Cornforth e Thomas (1990) destacam que, na cultura individualista e materialista do capitalismo, o apelo do trabalho em cooperativas, com o pressuposto da adesão voluntária e com objetivos sociais e solidários, é muito baixo. Esse apelo aumentaria com a restrição de alternativas decorrentes da reestruturação econômica e o desemprego, o que explicaria o porquê do declínio do cooperativismo no auge do fordismo e sua retomada atual.

Elementos culturais presentes no assalariamento, entendido como acesso a direitos de cidadania, dificultam a compreensão de uma proposta autogestionária na qual a divisão do trabalho entre os que pensam e os que fazem tenderia senão a desaparecer, pelo menos, a diminuir. O fato de as cooperativas de produção industrial terem 
no trabalho seu aspecto fundante e único capital dos novos "proprietários" resulta numa intensificação do trabalho inicial nem sempre compreendida e bem aceita. Some-se a isso a fragilidade econômica das cooperativas, que usualmente resultam de empresas falidas ou de programas de geração de renda decorrentes de movimentos sociais de trabalhadores ou da redução pragmática de custos empresariais.

Nos casos de recuperação de fábricas falidas, a questão tecnológica é um dilema. As empresas em crise falimentar deixam de investir em tecnologia e, quando as cooperativas assumem o controle, geralmente encontram máquinas obsoletas, às vezes danificadas, implicando dificuldades para os trabalhadores levarem o empreendimento adiante. As referências a dificuldades dessa ordem são recorrentes. Osório tratou dos teares recuperados pelos próprios trabalhadores na cooperativa formada no Rio Grande do Norte como condição para a fábrica voltar a operar (1988); Alves e Barroso deram um depoimento sobre problemas de equipamentos antigos na Coopervest de Aracaju (2000), que limitavam a expansão da produção; Tauile e Debaco (2002) destacaram os equipamentos antigos e obsoletos, que fazem com que as empresas cooperativas nasçam com uma estrutura de capital deficiente e sem capacidade de financiamento de capital de giro, o que compromete sua viabilidade.

Situação semelhante é encontrada em algumas cooperativas pragmáticas que funcionam como terceiras. Organizadas visando ao rebaixamento de custos, passam a realizar trabalho de montagem e acabamento de produtos (no caso visto aqui, calçados e confecções) com os equipamentos das fábricas cedidos em comodato aos trabalhadores. A maquinaria, em alguns casos, chega a ter mais de vinte anos de uso (Lima, 2002), mas atende ao objetivo da fase da produção, predominantemente de trabalho intensivo, na qual os imperativos tecnológicos são menores. Nesses casos, a substituição de máquinas deterioradas não constitui problema, pois as cooperativas funcionam, na prática, como setores das empresas, e estas se responsabilizam por questões que possam comprometer a produção. Usualmente, em proje- tos financiados por órgãos governamentais, ao contrário, a maquinaria é nova, comprada por meio de empréstimos de bancos estatais avalizados pelas empresas ou mesmo pelos órgãos governamentais. Quando os empréstimos não são pagos, geralmente por falta de encomendas das empresas, as máquinas podem ser arrestadas, inviabilizando as cooperativas.

Quanto à participação e à democratização do trabalho, estas não se constituem em prioridades para as cooperativas assim formadas. As assembléias de trabalhadores existem formalmente para legitimar decisões já tomadas. A organização do trabalho continua hierarquizada e os supervisores de fábricas decidem efetivamente o dia-a-dia da produção e algumas cooperativas contratam pessoal de gerência externo à cooperativa. Os diretores formais dessas cooperativas limitam-se a gerir a disciplina dos trabalhadores a partir das diretrizes e dos estatutos sugeridos pelas empresas. Os trabalhadores cooperados operam conforme as linhas de montagem tradicionais (confecções e calçados) com algumas variações. Eventualmente, há a instalação de ilhas de produção com equipes de trabalhadores, consideradas mais eficientes por possibilitar maior controle do trabalho realizado pelo operário e por responsabilizá-lo, perante a equipe, pela qualidade do material produzido e, em conseqüência, pelos ganhos de produtividade da equipe. Os treinamentos sobre qualidade e inovações organizacionais concentram-se no pessoal de supervisão.

Raramente os trabalhadores entendem as características e peculiaridades de uma cooperativa, considerando-a uma empresa semelhante às outras, exceto pela inexistência dos direitos que a empresa convencional garante aos empregados. Mesmo quando as empresas "parceiras" e os órgãos estatais oferecem cursos de cooperativismo aos trabalhadores, raramente seus princípios $\mathrm{e}$ propostas são assimilados. Os trabalhadores deparam-se com contradições entre os ensinamentos, o treinamento e o discurso apresentados nos cursos e a efetiva organização do trabalho vigente na cooperativa, geralmente taylorizada e fortemente hierarquizada, com a onipresença da empresa primeira no controle do processo de trabalho 
através de seus funcionários que "supervisionam" o serviço.

A possibilidade de os trabalhadores se perceberem proprietários da empresa é, portanto, restrita, apesar de estarem permanentemente sendo informados do caráter coletivo do empreendimento para efeito de envolvê-los no trabalho. Entretanto, dado que a organização do trabalho não difere daquela da empresa tradicional, fica difícil para o trabalhador entender que a empresa é dele e que existe alguma vantagem nisso.

Do ponto de vista desses trabalhadores cooperados, além de eles não terem carteira assinada o que na cultura dos trabalhadores é um símbolo de inclusão social -, a obrigação de dar conta das encomendas acarreta, muitas vezes, trabalho ininterrupto. As licenças e outros benefícios dependem da existência de fundos de reservas, previstos na legislação cooperativista, mas que pressupõem o funcionamento regular e relativamente estável das cooperativas. Como nem sempre isso acontece (mesmo com contratos de exclusividade com as empresas), o recebimento de alguns benefícios ficam adiados até a cooperativa "fazer caixa". Mesmo assim, existe uma tendência de as empresas pressionarem as cooperativas para a manutenção de fundos de reserva a fim de evitar problemas com a fiscalização das delegacias do Trabalho e da Procuradoria da República. Algumas empresas, mais precavidas, obrigam as cooperativas a descontarem dos ganhos dos cooperados o INSS, uma vez que os trabalhadores raramente o recolhem por conta própria, dado as baixas retiradas mensais.

Assim, as injunções do dia-a-dia das cooperativas contribuem para que os trabalhadores se identifiquem fortemente com as empresas "parceiras" e raramente se percebam membros das cooperativas. Basta dizer que em pequenas cidades nordestinas, para localizar as cooperativas, é necessário perguntar sobre a "cooperativa da fábrica tal".

A participação nas cooperativas é vista negativamente pelos trabalhadores, para quem a afiliação à cooperativa deve-se à falta de opção de empregos em sua região. Afirmam que, sem dúvida, sua situação melhorou: antes trabalhavam no meio rural ou viviam de expedientes urbanos, ra- ramente com experiência de trabalho assalariado. Mesmo assim, percebem a permanência na cooperativa como temporária, até "arrumarem alguma coisa melhor", de preferência numa empresa regular e com "direitos".

Em decorrência do caráter contraditório da organização das cooperativas pragmáticas, a rotatividade dos cooperados é grande, embora se reduza naquelas mais estáveis, nas quais a produção é continuada (algumas mandam para casa os trabalhadores quando não têm encomendas), não atrasam pagamentos e observam minimamente a legislação cooperativista.

Tais questões, embora reflitam uma forma específica de organização de cooperativa, não lhes são exclusivas. Mesmo em cooperativas formadas a partir de movimento de trabalhadores para recuperação de empregos, são grandes os problemas de adaptação. Primeiro com a redução de quadros e com a rotatividade que, em alguns casos, tendem a ser elevadas. Na formação das cooperativas, o número de trabalhadores que aceitam continuar é reduzido, comparativamente ao número de trabalhadores existentes anteriormente e que preferem procurar outro emprego. O mesmo se pode dizer dos quadros mais qualificados que, em grande parte, não aderem a proposta de cooperativa. Os que permanecem têm dificuldades de entender a nova situação de autogestão, de serem trabalhadores e patrões ao mesmo tempo. Assim, problemas de disciplina, de hierarquia e de participação no processo de adaptação dos trabalhadores são freqüentemente encontrados.

Outros fatores contribuem para a falta de participação dos associados: um deles estaria relacionado à baixa escolaridade da maioria dos trabalhadores; outro, ao fato de inexistir o hábito de se manifestarem em assembléia, o que poderia decorrer da reduzida confiança nas suas possibilidades de intervenção; ou, ainda, o fato de considerarem que a administração não seria um problema deles (Singer, 2002; Holzmann, 2001; Maciel e Souto, 2002; Maciel, 2002; Alves e Barroso, 2000). Podemos destacar que a falta de instrução formal dos trabalhadores afeta particularmente os que ocupam cargos de direção. Segundo Tauile e Debaco (2002), mesmo com o conhecimento prático 
do processo produtivo, a carência de conhecimentos técnico-organizacionais e de questões mercadológicas aumenta as dificuldades no processo de construção de um corpo técnico adequado aos desafios impostos pela proposta autogestionária e sua inserção num mercado competitivo.

Em grande medida, os trabalhadores continuam agindo como empregados e nem sempre percebem a diferença da cooperativa e da empresa com o patrão (Souto, 2002). Isso depende de como, no processo de organização e consolidação das cooperativas, a questão hierárquica é resolvida. A participação restrita do conjunto dos trabalhadores termina por cristalizar hierarquias, reproduzindo situações anteriores à cooperativa, com a separação crescente do pessoal da administração do pessoal da produção. ${ }^{9}$

A adesão de novos membros cria duas situações distintas com relação ao envolvimento com o empreendimento cooperativo: a presença de trabalhadores assalariados ou a aceitação de novos associados. A aceitação de novos membros resulta em problemas de envolvimento com a cooperativa, já que os novos não participaram das lutas de transformação das empresas em cooperativas e apresentam um envolvimento menor. A contratação de assalariados cria um dualismo entre os trabalhadores associados que enfrentam o dilema de serem os patrões e, ao mesmo tempo, terem menos direitos que seus colegas assalariados protegidos, em certa medida, pela legislação trabalhista.

A manutenção da divisão do trabalho tradicional é outro fator que compromete o caráter democrático da gestão, assim como a disciplina pela incompreensão, por parte de trabalhadores, do significado do trabalho cooperativo. Necessidades da produção exigem, às vezes, horários fixos de início e término do trabalho e nem sempre os trabalhadores, agora associados, entendem que a disciplina é condição de funcionamento da cooperativa. Avanços na democratização interna e na flexibilidade dos processos produtivos no trabalho, o trabalho em grupo e a polivalência funcional podem agir no sentido de mudanças nessa divisão, embora também apresentem a necessidade de especializações. Essas questões são percebidas como uma necessidade de educação cooperativa permanente, o que levaria, a médio e a longo prazo, à superação dessas barreiras.

Por fim, podemos destacar que o fato de as cooperativas trabalharem, em grande parte, como terceirizadas para outras empresas reflete negativamente na sua autonomia. Nas cooperativas pragmáticas, significa o atrelamento direto às empresas parceiras. Se a vinculação é com uma empresa única, a situação pode ficar mais grave. Nos anos de 1990, cooperativas cearenses ficaram quase seis meses sem encomendas em função da crise Argentina, país para o qual a empresa parceira destinava parte de sua produção. Com isso, os trabalhadores ficaram todo esse tempo sem receber nada.

"Pragmáticas" ou "defensivas" a vinculação das cooperativas a contratos de terceirização mantém uma relação de dependência entre a empresa primeira e a terceira, o que pode ser generalizado a outras relações empresariais. Geralmente a empresa determina a produção, como deve ser organizada, os padrões etc. Um exemplo dessa situação em cooperativa defensiva é a Coopervest de Aracaju em sua dependência inicial ao grupo Sellinvest, minimizada posteriormente com a abertura de marca e lojas próprias.

A discussão a respeito do ciclo de vida das cooperativas é recorrente na literatura sobre o tema, desde o final do século XIX. Fundamenta-se na perspectiva da degeneração dos princípios, marcada pela erosão gradual da democracia interna, pela contração de gerentes e trabalhadores assalariados, e pela transformação progressiva em empresa regular. $\mathrm{Na}$ análise de experiências internacionais, verifica-se um padrão variado de funcionamento das cooperativas, tal qual existe nas empresas regulares. No caso das pequenas cooperativas, estas enfrentam situações comuns a pequenas empresas, e sua propensão ao fechamento decorre dos problemas de mercado típico de pequenos negócios. No caso de cooperativas maiores, as situações são distintas. Mondragón, o modelo de cooperativa adaptado aos tempos de reestruração econômica, tem praticamente cinqüenta anos de funcionamento, assim como algumas cooperativas francesas e italianas, em que pese à discussão sobre a observância aos princípios do cooperativismo. 
No Brasil, as cooperativas de produção industrial crescem em todos os formatos a partir do final dos anos de 1980 e início da década seguinte. Parte delas está completando dez anos de funcionamento com êxitos diferenciados, o que dificulta as considerações sobre a viabilidade ou não de sua continuidade. Entretanto, devemos destacar que esses empreendimentos têm recebido apoio cada vez maior de instituições sociais, de ONGs, do Estado e até de empresas (embora com objetivos diferenciados) diante do novo quadro econômico, o que pode indicar uma tendência de crescimento.

\section{Perspectivas}

Embora as cooperativas apareçam historicamente no movimento operário como possibilidade autogestionária e de democracia no trabalho, sua implementação efetiva defronta-se com diferentes contradições e depende de injunções políticas e econômicas: surgem sempre em momento de crise econômica e visam a atenuar situações de desemprego. Para Quijano (2002), as regras que regem as cooperativas são as do mercado e do salário, e o caráter de reciprocidade ou solidariedade operaria externamente às relações de trabalho, a partir da decisão consciente de seus membros. Essa consciência deriva de um processo complexo, pois raramente significa uma situação de materialidade objetiva mais satisfatória para seus membros do que a vivida anteriormente, o que explica o desinteresse por esse tipo de empreendimento em momentos de estabilidade e crescimento econômico. O caráter voluntário da adesão às cooperativas fica comprometido em contextos de crise econômica, nos quais as possibilidades de ocupação são reduzidas. Fica a questão se é uma alternativa à exploração capitalista, ou à falta dessa mesma exploração.

Dois elementos presentes na organização das cooperativas destacam-se no debate: a externalidade de seus organizadores, ou seja, a presença do Estado, de sindicatos, ONGs e mesmo empresas; e sua heterogeneidade no espectro ideológico, que vai de grupos empresariais a movimentos socialis- tas. Todos com a perspectiva, de certa forma contraditória, de inserção no mercado. Haveria uma lógica diferente na inserção, conforme a perspectiva ideológica? Falta saber qual seria essa lógica.

As cooperativas atenderiam, dependendo de quem as organiza, desde rebaixamento de custos para empresas, passando pela formação de novos empreendedores capitalistas, até uma complexa democracia no trabalho. Ambas podem, de certa forma, atender a propostas de geração de renda e de manutenção e criação de empregos num contexto no qual estes estão se reduzindo. Daí o diferencial, como assinalado por Quijano, estaria na disposição dos membros em participarem desses empreendimentos e na sua adesão ideológica aos princípios autogestionários.

Nesse quadro, o crescimento da economia solidária mostra uma saída possível, uma política de desenvolvimento sustentável paralela às instituições capitalistas regulares e, contraditoriamente, integrada a ela. Várias cooperativas pragmáticas fecham quando são abandonadas pelas empresas primeiras que as sustentam. O apoio a esses empreendimentos poderia alterar o quadro. O combate explícito às cooperativas não solidárias talvez fosse mais efetivo se considerasse a possibilidade de transformação de cooperativas não solidárias em solidárias por meio da educação cooperativa de seus membros sobre os princípios do cooperativismo e pelo debate democrático na sociedade.

A distinção entre cooperativas verdadeiras e falsas reintroduz, como afirmamos no início, um debate secular, assim como retoma as questões sobre a sua utilização pelo capital e a sua possível degenerescência. As transformações do capitalismo, embora não tenham alterado seus fundamentos, alteraram as perspectivas da luta dos trabalhadores pelo socialismo ou por formas mais igualitárias de organização social. A discussão sobre mudanças na direção de uma sociedade solidária nos marcos da sociedade capitalista pressupõe pensar um processo de mudança cultural a médio e a longo prazo. Nesse ínterim, a criação de uma cultura associativa é um processo possível, mas lento, o que indica que as cooperativas refletirão, ainda por um bom tempo, a falta de opção dos trabalhadores mais do que uma escolha 
efetiva pela autonomia e solidariedade. A contraposição entre alternativa à espoliação do trabalho versus opção pela autonomia solidária ganha relevo ainda maior ao considerarmos a funcionalidade da organização de cooperativas em uma conjuntura de flexibilidade e crescente fragilidade dos direitos sociais.

\section{NOTAS}

1 As definições de cooperativas de trabalho e de produção industrial não são muito precisas. As de trabalho, segundo a Organização das Cooperativas brasileiras reuniriam diversos tipos de profissionais para a prestação de serviço para terceiros, e a de produção industrial organizariam a produção como um todo, tal qual uma fábrica comum, onde o produto final é resultado do trabalho coletivo (Lima, 1998). Utilizaremos os termos aqui como sinônimos.

2 Oakeshott (1978) refere-se à situação obscura das cooperativas italianas no período fascista, que teriam recebido isenções de impostos e outras vantagens do Estado.

3 Sobre a experiência iuguslava, ver Prasnikar e Prasnikar (1986).

4 Sobre os Kibbutz israelenses, ver Rosner (1991).

5 Sobre Mondragón, ver White e White (1989), Singer (2000) e Moye (1993).

6 Uma crítica ao modelo autogestionário de Mondragón é feita por Kasmir (1996).

7 Ver adiante a definição de economia solidária.

8 Kasmir faz referência às reclamações do sindicato sobre a baixa adesão dos trabalhadores cooperados de Mondragón no movimento operário local (1996).

9 Situação igualmente encontrada por Kasmir em Mondragón (1996).

\section{BIBLIOGRAFIA}

ALVES, Maria Irene Santos \& BARROSO, Aderaldo. (2000), "Coopervest", in O. S. Pon- tes Jr. (org.), Mudanças no mundo do trabalho: cooperativismo e autogestão, Fortaleza, Expressão.

ANTEAG. ( 2000), Autogestão: construindo uma nova cultura de relações de trabalbo. São Paulo, ANTEAG.

BADSTONE, Eric. (1983), "Organization and orientation: a life cycle model of French co-operatives". Economic and Industrial Democracy, 4: 139-161.

BALDACCHINO, Godfrey. (1990), "A war of position: ideas on a strategy for worker cooperative development". Economic and Industrial Democracy, 11: 463-482.

CAVALCANTI, Clóvis (org.). (1988), No interior da economia oculta: estudos de caso de uma pesquisa de avaliação do desenvolvimento de base no Norte e no Nordeste do Brasil. Recife, Fundação Joaquim Nabuco/Editora Massangana.

CLARKE, T. (1977), "Industrial democracy: the institutionalised suppression of industrial conflict?, in T. Clarke e L. Clements (eds.), Trade unions under capitalism, Londres, Fontana (Apud Eric Badstone, (1983), "Organization and orientation: a life cycle model of French co-operatives". Economic and Industrial Democracy, 4: 139-161.

CORNFORTH, Chris. (1983), "Some factors affecting the success or failure of worker cooperatives: a review of empirical research in the United Kingdom". Economic and Industrial Democracy, 4:163-190.

CORNFORTH, Chris \& THOMAS, Alan. (1990), "Cooperative development barriers: support structures and cultural factors". Economic and Industrial Democracy, 11: 451-461.

CRUZ, Antonio. (2001), Uma contribuição crítica às políticas públicas de apoio à economia solidária. São Paulo (mimeo.). 
HERRANZ, Roberto \& HOSS, Dietrich. (19901991), "División del trabajo entre centro y periferia: cooperativas y industrialización difusa em Galícia”. Sociologia del Trabajo, Nueva Época, 11, inverno.

HOLZMANN, Lorena. (2001), Operários sem patrão: gestão cooperativa e dilemas da democracia. São Carlos, Editora da UFSCar.

KASMIR, Sharryn. (1996), The myth of Mondragón: cooperatives, politics and workingclass life in a Basque Town. Albany, State University of New York Press.

LIMA, Jacob Carlos. (1998), "Cooperativas de produção industrial: autonomia e subordinação do trabalho", in N. A. Castro e C. S. Dedecca, A ocupação na América Latina: tempos mais duros, São Paulo/Rio de Janeiro, Alast.

. (2002), As artimanhas da flexibilização: o trabalho terceirizado em cooperativas de produção. São Paulo, Terceira Margem.

LIMA, Jacob Carlos \& ARAÚJO, Neyara. (1999), "Para além do novo sindicalismo: a crise do assalariamento e as experiências com trabalho associado", in I. J. Rodrigues (org.), O novo sindicalismo: vinte anos depois, Petrópolis, Vozes.

LOUIS, Raymond. (1986), Cooperativas de mano de obra, en regresión o expansión? Madrid, Ministério Del Trabajo y Seguridad Social, Colección Informes OIT.

LUXEMBURG, Rosa. (1979), "Reforma o revolución", in R. Luxemburg, Obras escogidas, Bogotá, Editorial Pluma, Tomo I.

MACIEL, Vera de Fátima. (2002), "Trabalhadores gerindo fábricas: um estudo em cinco empresas do setor metal-mecânico", in R. Valle, Autogestão: o que fazer quando as fábricas fecham?, Rio de Janeiro, Relume-Dumará.

MACIEL, Vera de Fátima \& Souto, Luiz Antonio. (2002), "Visão sintética dos resultados da pesquisa exploratória em empresas pioneiras", in R. Valle, Autogestão: o que fazer quando as fábricas fecham?, Rio de Janeiro, Relume-Dumará.

MAGALHÃES, Reginaldo Sales. (2001), Sindicatos, cooperativas e socialismo. Texto formulado como subsídio à exposição da CUT no debate sobre cooperativas, sindicatos e socialismo, promovido pelo PT em 7 de maio (mimeo.).

MAGALHÃES, Reginaldo Sales \& TODESCHINI, Remígio. (2000),"Sindicalismo e economia solidária: reflexões sobre o projeto da CUT", in P. Singer e A. R. Souza, $A$ economia solidária no Brasil: a autogestão como resposta ao desemprego, São Paulo, Contexto.

MANDEL, E. (1975), "Self-management: dangers and possibilities". International, 2/3:3-9 (Apud Eric Badstone (1983), "Organization and orientation: a life cycle model of French co-operatives". Economic and Industrial Democracy, 4: 139-161.

MARX, Karl. (1977), "Manifesto do lançamento da Associação Internacional dos Trabalhadores, 1864", in K. Marx e F. Engels, Textos 3, São Paulo, Edições Sociais.

MEDEIROS, Alzira \& MARTINS, Paulo Henrique (orgs.). (2003), Economia popular e solidária: desafios teóricos e práticos. Recife, Bagaço.

MELLOR, Mary; HANNAH, Janet \& STIRLING, John. (1988), Worker cooperatives in theory and practice. Milton Keynes, Philadelphia, Open University Press.

MOREIRA, Maria Vilma Coelho. (1997), "Cooperativismo e desenvolvimento: o caso das Cooperativas de Confecção do Maciço de Baturité, Ceará”. Politica e Trabalho, 13: 55-76.

MOYE, A. Melissa. (1993), "Mondragón: adapting co-operative structures to meet the demands of a changing environment". 
Economic and Industrial Democracy, 14: 251-276.

NAKANO, Marilena. (2000), "ANTEAG: autogestão como marca", in P. Singer e A. R. Souza, A economia solidária no Brasil: a autogestão como resposta ao desemprego, São Paulo, Contexto.

NASCIMENTO, Maria de Fátima. (1993), O próximo e o distante: histórias e estórias de um bairro e uma fábrica de João Pessoa. Dissertação de mestrado, João Pessoa, UFPB (mimeo.).

OAKESHOTT, Robert. (1978), The case for Worker's Co-ops. Londres/Henley/Boston, Routledge/Kegan Paul.

OSÓRIO, Carlos. (1988), "Autogestão com sucesso: o caso da Cooperativa Mista dos Têxteis do Rio Grande do Norte", in C. Cavalcanti (org.), No interior da economia oculta: estudos de caso de uma pesquisa de avaliação do desenvolvimento de base no Norte e no Nordeste do Brasil, Recife, Fundação Joaquim Nabuco/Editora Massangana.

PRASNIKAR, Janez \& PRASNIKAR, Vesna. (1986), "The Yugoslav self-managed firm in historical perspective". Economic and Industrial Democracy,7: 167-190.

PONTES Jr., Osmar de Sá. (2000), Mudanças no mundo do trabalho: cooperativismo $e$ autogestão. Fortaleza, Expressão.

QUIJANO, Aníbal. (2002), "Sistemas alternativos de produção?", in B. S. Santos (org.), Produzir para viver: os caminhos da produção não capitalista, Rio de Janeiro, Civilização Brasileira.

REIS, Cinthia Regina Nunes. (2003), Cooperativismo e cooperativas de trabalho: o caso dos "Grupos de Trabalhadores" de Lima Campos, Maranhão. Dissertação de mestrado, Recife, UFPe (mimeo.).

ROSNER, Menachem. (1991), "Worker ownership, ideology and social Structure in 'Third- way' Work Organizations". Economic and Industrial Democracy,12: 369-384.

SANTOS, Boaventura de Sousa \& RODRÌGUEZ, César. (2002), "Introdução: para ampliar o cânone da produção", in B. S. Santos (org.), Produzir para viver: os caminhos da produção não capitalista. Rio de Janeiro, Civilização Brasileira.

SINGER, Paul. (2000), "Economia solidária: um modo de produção e distribuição", in $\mathrm{P}$. Singer e A. R. Souza, A economia solidária no Brasil: a autogestão como resposta ao desemprego, São Paulo, Contexto.

.(2002), "A recente ressureição da economia solidária no Brasil", in B. S. Santos (org.), Produzir para viver: os caminhos da produção não capitalista, Rio de Janeiro, Civilização Brasileira.

.(2003), "Economia Solidária", in A. D. Cattani (org.), A outra economia, Porto Alegre, Veraz Editores.

SINGER, Paul \& SOUZA, André Ricardo. (2000), A economia solidária no Brasil: a autogestão como resposta ao desemprego. São Paulo, Contexto.

SOLA, José Roberto. (2000), A organização do trabalho no contexto da autogestão: a experiência da ANTEAG, in O. S. Pontes Jr. (org.), Mudanças no mundo do trabalho: cooperativismo e autogestão. Fortaleza, Expressão.

SOUTO, Luiz Antonio. (2002), "Estudo de caso em uma das empresas pioneiras", in R. Valle (org.), Autogestão: o que fazer quando as fábricas fecham?, Rio de Janeiro, Relume-Dumará.

TAUILE, José Ricardo \& DEBACO, Eduardo Scotti. (2002), "Autogestão no Brasil: a viabilidade econômica de empresas geridas por trabalhadores". Artigo apresentado no VII Encontro Nacional de Economia Política, Curitiba (mimeo.). 
THORNLEY, Jenny. (1983), "Worker's co-operatives and trade unions: the Italian experience". Economic and Industrial Democracy, 4: 321-344.

VALLE, Rogério. (2002), Autogestão: o que fazer quando as fábricas fecham?. Rio de Janeiro, Relume-Dumará.

WEBB, S. \& WEBB, B. (1914), "Co-operative production and profit sharing". Special Supplement to the New Statesman, 2 (45).

WHITE, Willian Foote \& WHITE, Kathleen King. (1989), Mondragón: mas que una utopia. San Sebastian, Editorial Txertoa. 


\section{O TRABALHO AUTOGESTIO- NÁRIO EM COOPERATIVAS DE PRODUÇÃO: O PARADIG- MA REVISITADO}

Jacob Carlos Lima

\section{Palavras-chave}

Cooperativas de trabalho e produção; Autogestão; Trabalho flexível; Trabalho associado; Terceirização.

O objetivo deste trabalho é analisar a multiplicação de cooperativas de trabalho e produção percebidas ora de forma pragmática para redução de custos empresariais, ora como alternativa de maior autonomia e democratização do trabalho para os trabalhadores na perspectiva da Economia Solidária. Procurou-se verificar as similaridades e as diferenças na organização das cooperativas, recuperando algumas situações específicas, e as dificuldades identificadas na formação de uma cultura autogestionária entre os trabalhadores, tendo em vista que o trabalho nessas cooperativas, mais que uma alternativa voluntária, responde a um quadro de desemprego estrutural.

\section{LE TRAVAIL D'AUTOGESTION DANS LES COOPÉRATIVES DE PRODUCTION: LE PARADIG- ME RÉÉTUDIÉ}

Jacob Carlos Lima

\section{Mots-clés}

Coopératives de travail et de production; Autogestion; Travail flexible; Travail associé; Sous-traitance.

Cet article analyse la croissance des coopératives de travail et de production à partir des années 1990. Ces coopératives sont perçues tantôt de façon pragmatique, en vue de la réduction des coûts d'entreprise ou d'une garantie de revenu, tantôt en tant que source possible d'une plus grande autonomie et de démocratisation des relations de travail. Nous avons tenté d'identifier les similitudes et les différences dans leur organisation, en présentant quelques situations spécifiques concernant la formation d'une culture autogestionnaire. Une des difficultés majeures de l'analyse a été de démontrer que le travail dans ces coopératives ne constitue pas une alternative ancrée dans la volonté des travailleurs, mais répond plutôt à une situation de chômage structurel.

\section{SELF-MANAGEABLE WORK IN PRODUCTION COOPERATIVES: THE REVISITED PARADIGM}

Jacob Carlos Lima

\section{Keywords}

Production and work cooperatives; Self-management; Flexible work; Associate work; Outsourcing.

The objective of this article is to analyze the multiplication of work cooperatives in Brazil starting in the 1990's. These cooperatives were either a pragmatic way for reduction of business costs or a possibility for generating income and democratization of work relations. The author tries to verify the similarities and differences in the organization of such cooperatives, examining some specific situations and identifying difficulties in the formation of a culture of self-management which are due to the fact that work in those cooperatives, rather than being a voluntary alternative, is a way to resolve problems of unemployment. 